Article

\title{
Gas-Phase Mass-Transfer Resistances at Polymeric Electrolyte Membrane Fuel Cells Electrodes: Theoretical Analysis on the Effectiveness of Interdigitated and Serpentine Flow Arrangements
}

\author{
Elisabetta Arato *, Marzia Pinna, Michela Mazzoccoli and Barbara Bosio \\ Department of Civil, Chemical and Environmental Engineering; University of Genoa, Via Opera Pia 15, \\ Genoa-16145, Italy; mirzia@zsis.it (M.P.); michela.mazzoccoli@unige.it (M.M.); barbara.bosio@unige.it (B.B.) \\ * Correspondence: elisabetta.arato@unige.it; Tel.: +39-010-3532926 or +39-346-7439478 \\ Academic Editor: Jinliang Yuan \\ Received: 30 December 2015; Accepted: 15 March 2016; Published: 23 March 2016
}

\begin{abstract}
Mass transfer phenomena in polymeric electrolyte membrane fuel cells (PEMFC) electrodes has already been analyzed in terms of the interactions between diffusive and forced flows. It was demonstrated that the whole phenomenon could be summarized by expressing the Sherwood number as a function of the Peclet number. The dependence of Sherwood number on Peclet one $\mathrm{Sh}(\mathrm{Pe})$ function, which was initially deduced by determining three different flow regimes, has now been given a more accurate description. A comparison between the approximate and the accurate results for a reference condition of diluted reactant and limit current has shown that the former are useful for rapid, preliminary calculations. However, a more precise and reliable estimation of the Sherwood number is worth attention, as it provides a detailed description of the electrochemical kinetics and allows a reliable comparison of the various geometrical arrangements used for the distribution of the reactants.
\end{abstract}

Keywords: transport phenomena; modeling; polymeric membrane fuel cells; gas flow mode

\section{Introduction}

In a previous work [1], attention was paid to the gas-phase mass transfer occurring on polymeric electrolyte membrane fuel cells (PEMFC) electrodes according to the different flow arrangements used (simply parallel, serpentine, and totally or partially interdigitated). The various possible diffusive regimes were highlighted and the interaction between diffusive and forced flows was defined in terms of Peclet numbers, so that the overall diffusive resistance could be expressed in terms of a Sherwood number as a function of a Peclet number.

A number of works can be found in literature that analyze the PEMFC performance at different degree of detail ranging from traditional [2-9], interdigitated [7,10-18] and serpentine [4,7,8,12,16,19-22] cells. A local description of the hydration condition of the membrane allows a reliable prediction of cell performance $[2,3,7,10,11,18]$ and the simulation of different flow fields indicates that the interdigitated flow channel gives in general better results than the serpentine flow channel configuration $[11,18]$. A better understanding of the role of gas mass transfer was shown to be effective in explaining some important differences in the performances of these cells [23], especially in terms of limit current.

In a second work [24], the comparison between interdigitated and serpentine geometries was carried out by calculating and comparing the head losses in contiguous channels.

The present work tries to provide a more precise calculation of the Sherwood number as a function of the Peclet number $\mathrm{Sh}(\mathrm{Pe})$, starting with the solution of a simplified partial derivative system of mass and momentum balance equations on the porous medium close to a PEMFC electrode. 
The Sh(Pe) function was approximately deduced [1] by determining and making reference to three different flow regimes. A more rigorous numerical description of this first evaluation can serve to confirm and refine the approximate results. On the contrary, any approximate analytical solution designed to circumvent the aforesaid three-flow-regime schematization may be partially inappropriate and physically inconsistent; for instance, an approximate analytical solution roughly appropriate for pure diffusion or low velocities has been shown to be unreliable for the high velocity of migration through the porous zone [1].

In this sense, a simple numerical approach to the solution has been used for this work. The specific scopes and usefulness of this approach need a little discussion. On the one hand, specific and detailed simulation approaches of local kinetics and flow fields in PEMFC electrodes can be found in the literature [25]; our approach aims to achieve a mean kinetic expression in order to avoid the repetition of a cumbersome and time consuming calculation load for each point (or finite element) of the electrode. Therefore, the ultimate goal is to provide simple correlations to estimate Sherwood numbers (that is, mass transfer effects and limit currents) and their combination with electrochemical kinetics. On the other hand, while pursuing this result, reference can be made to a number of simplifying conditions, such as the ones of a diluted reagent and limiting diffusion (limit current); it will be shown that the difference between these reference conditions and real local conditions on the electrode (non diluted reagents and significant bulk flow effects, intermediate ranges of current, etc.) can be taken into account subsequently, in the form of corrective coefficients or averaging methods. In such a way, different levels of approximation for the estimation of the local electrochemical kinetics are available. Neglecting here micro- and mesoscopic levels [26], the more accurate approach traditionally consists of detailed numerical simulation tools $[7,8,11,16,21,27]$, which can be heavy to handle when commercial size cells or stack are considered. Advanced analytical studies have also been recently proposed, such as the fractal approach [28], which are useful to assess the main relationships which rule phenomena and influence performance. On the other hand, simple expressions that summarize local numerical calculations and that are physically based on the consideration of reference flow regimes can also be adopted. The present work will demonstrate that these approaches are substantially significant and useful for rapid, preliminary and correct calculations However, the errors in these latter approximate solutions are not fully negligible: only a more precise and reliable estimation of the Sherwood numbers can provide detailed and accurate correlations for the local electrochemical kinetics. This estimation can lead to a useful comparison of the various geometrical arrangements used for the distribution of the reactants. For our purpose, an intermediate level of approximation is generally sufficient for a reliable evaluation of local Sherwood numbers, so that a simplified numerical model is here proposed.

As a matter of fact, both interdigitated and serpentine cells can be operated at high Sherwood numbers corresponding to high limit currents $[1,3,24]$, but both are correspondingly penalized by higher head losses than those for traditional cells. A better understanding of these features will allow us to plan more effectively the geometrical optimization of the cell. In order to reach uniform and high Sherwood numbers and low head losses, some technological problems could be still solved and even interdigitated cells do not seem to be a completely suitable solution. The proposed partially interdigitated configuration [24], the use of special distribution grids [29] or feeding solutions [16,30] could be considered as promising steps in the right direction.

\section{An Improved Calculation of $\mathrm{Sh}(\mathrm{Pe})$}

\subsection{Steps in the Calculation Procedure and Simplifying Hypotheses}

A geometrical scheme of the system, for which the Sherwood number was calculated, is given in Figure 1 in reference to a parallel-channel configuration, such as the one typically used in interdigitated cells. The section of the contiguous gas channels is shown with the porous layer through which the reaction gas has to migrate and diffuse before reaching the reaction site in the electro-catalytic layer. The spatial domain considered has a rectangular $\mathrm{H}^{*}(\mathrm{~B}+\mathrm{D})$ section, where $\mathrm{H}$, on the $x$-axis, is the 
thickness of the diffusion layer and D, on the $y$-axis, is the length between one channel and the next; $B$ is the size of the transversal section of the gas channels, which is simply assumed to be a square here.

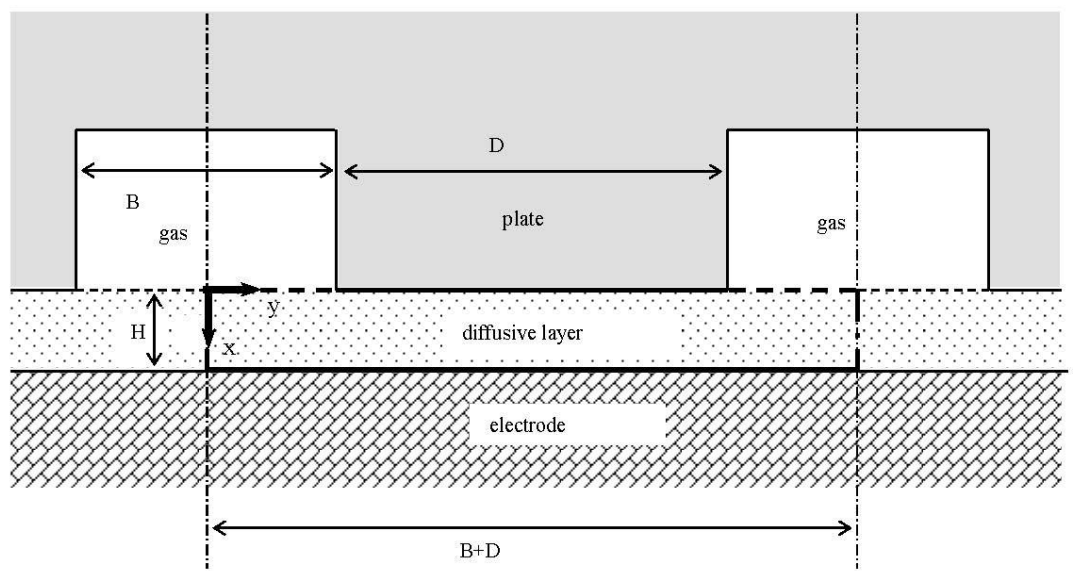

Figure 1. A geometrical scheme of the system (reference spatial domain: $0 \leqslant x \leqslant \mathrm{H}$ and $0 \leqslant y \leqslant B+D$ ).

The calculation procedure that provides a more precise evaluation of the Sherwood number, that is the mass transfer resistances to the electrode, consists of three successive operations or steps: the calculation of

- the flow field;

- the composition field;

- the overall flux to the electrode.

Initially, the following simplifying hypotheses were assumed:

1. steady state;

2. two-dimensional geometry;

3. constant and uniform properties in the gas phase;

4. viscous regime inside the porous medium;

5. instantaneous reaction at the active boundary (electrode surface);

6. null orthogonal velocity at all the boundaries.

The first of these hypotheses is quite obvious, as the characteristic time of the system is very fast, typically much less than $1 \mathrm{~s}$.

The same can be said for the second hypothesis, as the characteristic length of the third dimension is much greater than the other two.

The third hypothesis requires negligible variations in the temperature and pressure around a reference or mean value.

The fourth implies a limit on the velocity through the porous layer, depending on the pore diameter. As a matter of fact, the Reynolds numbers of the medium, if based on the pore size, are normally lower than one, so that the inertial forces are negligible in relation to pressure forces. Moreover, as the fluid is a gas, gravitational forces are also negligible.

The fifth point means that the Sherwood number is calculated in correspondence to a complete mass transfer control, so that the Sherwood number and, then, the transport coefficient simply correspond to the limit current.

The sixth is perhaps the more problematic hypothesis: in particular, as it will be seen in the following sections, it could seem quite unreal for the electrode surface, as the occurrence of a reaction automatically implies a bulk flow to the electrode. On the other hand, this flow tends to become negligible compared to the diffusive flow when the reactant is very dilute. For a concentrated reactant, the introduction of a stagnant film correction is normally sufficient for a better estimation [31]. 


\subsection{The Flow Field}

As discussed [1], a good estimation of the velocity field and the corresponding mean velocity values in the porous medium close to the electrode is necessary for a good estimation of the Sherwood number and the limit current. Making reference to a typical interdigitated geometry (see Figure 1) and under the conditions of diluted reagent, unchanging density and viscous flow in the gas phase, the momentum balance equations can be reduced to the Darcy form:

$$
\mathbf{v}=-(\mathrm{K} / \mu) \operatorname{grad} \mathrm{P}
$$

This equation and the continuity equation ( $\operatorname{div} \mathbf{v}=0)$ imply that the pressure field satisfies the Laplace equation. Moreover, the invariance of the properties (in particular density, viscosity and permeability) makes it possible to separate the flow and the composition problems, so that the former can be solved in a straightforward way. In conclusion, we have to solve the system:

$$
\begin{gathered}
\partial^{2} \mathrm{P} / \partial \mathrm{X}^{2}+\partial^{2} \mathrm{P} / \partial \mathrm{Y}^{2}=0 \\
\mathrm{v}_{\mathrm{x}}=-(\mathrm{K} / \mu) \partial \mathrm{P} / \partial \mathrm{X} ; \mathrm{v}_{\mathrm{y}}=-(\mathrm{K} / \mu) \partial \mathrm{P} / \partial \mathrm{Y}
\end{gathered}
$$

Once the reference velocity:

$$
\mathrm{v}_{\mathrm{xr}}=-(\mathrm{K} / \mu)(\partial \mathrm{P} / \partial \mathrm{X})_{\mathrm{X}=0, \mathrm{Y}=0}
$$

the dimensionless permeability and geometry parameters:

$$
\mathrm{k}=\mathrm{K}\left(\mathrm{P}_{1}-\mathrm{P}_{2}\right) / \mu \mathrm{Hv}_{\mathrm{xr}} ; \mathrm{b}=\mathrm{B} / \mathrm{H} ; \mathrm{d}=\mathrm{D} / \mathrm{H}
$$

and the dimensionless variables:

$$
\begin{gathered}
\mathrm{p}=\left(\mathrm{P}-\mathrm{P}_{2}\right) /\left(\mathrm{P}_{1}-\mathrm{P}_{2}\right) ; \mathbf{u}=\mathbf{v} / \mathrm{kv}_{\mathrm{xr}} \\
\mathrm{x}=\mathrm{X} / \mathrm{H} ; \mathrm{y}=\mathrm{Y} / \mathrm{H}
\end{gathered}
$$

are defined, the flow problem can be written in the compact form:

$$
\begin{gathered}
\partial^{2} p / \partial x^{2}+\partial^{2} p / \partial y^{2}=0 \\
u_{x}=-\partial p / \partial x ; u_{y}=-\partial p / \partial y
\end{gathered}
$$

with the boundary conditions on the pressure field:

$$
\begin{array}{ccc}
\mathrm{x}=0 & 0<y<b / 2 & \mathrm{p}=1 \\
& b / 2<y<b / 2+d & \partial p / \partial x=0 \\
\mathrm{x}=1 & b / 2+d<y<b+d & \mathrm{p}=0 \\
\mathrm{y}=0 & 0<y<b+d & \partial p / \partial x=0 \\
\mathrm{y}=\mathrm{b}+\mathrm{d} & 0<x<1 & \partial p / \partial y=0 \\
& 0<x<1 & \partial p / \partial y=0
\end{array}
$$

These conditions simply imply that the pressure difference between the two contiguous channels, $\mathrm{P}_{1}$ and $\mathrm{P}_{2}$, is known; the velocity field close to the solid boundaries is parallel to them; and a symmetry condition can be applied to the channel axis. In particular, it is worth noting again that the condition at $\mathrm{x}=1(\mathrm{X}=\mathrm{H})$ is questionable: it implies that $\mathrm{v}_{\mathrm{X}}=0$ at the electrocatalyst, which is only true for a dilute gas. In fact, the electrochemical reaction at the electrode and its stoichiometry are consistent, for a non-dilute gas, with a significant velocity orthogonal to the electrode (entering the electrode of a PEMFC cathode and leaving the electrode of a PEMFC anode). However, this problem is of secondary importance and can be discussed in terms of corrections to more general results. 
For a given geometry, the system Equations (6) and (7) provides only one solution. Once $p(x, y)$ is known, the reference velocity $\mathrm{v}_{\mathrm{xr}}$ can be calculated for any given set of the other input variables, $\mathrm{P}_{1}$, $\mathrm{P}_{2}, \mathrm{~K}, \mu$, as:

$$
\mathrm{v}_{\mathrm{xr}}=-(\mathrm{K} / \mu \mathrm{H})\left(\mathrm{P}_{1}-\mathrm{P}_{2}\right)(\partial \mathrm{p} / \partial \mathrm{x})_{\mathrm{x}=0, \mathrm{y}=0}
$$

and, then, the fields of the dimensional output variables $P, v_{x}, v_{y}$ can be easily obtained. In more precise terms, the mean migration velocity can be defined as:

$$
\mathrm{v}_{\mathrm{ym}}=(\mathrm{K} / \mu \mathrm{H})\left(\mathrm{P}_{1}-\mathrm{P}_{2}\right)\left(\int_{0,1} \mathrm{u}_{\mathrm{y}} \mathrm{dx}\right)_{\mathrm{b} / 2<\mathrm{y}<\mathrm{b} / 2+\mathrm{d}}
$$

\subsection{The Peclet Numbers}

The Peclet numbers of the system can be defined in terms of the effective diffusivity inside the porous medium, $D_{A}$, a characteristic velocity $\left(v_{r}\right.$ or $\left.u\right)$ and various characteristic lengths $(H, D$, $\left.\mathrm{H}^{2} / \mathrm{D}, \ldots\right)$ :

$$
\mathrm{Pe}_{\mathrm{r}}=\mathrm{Hv}_{\mathrm{xr}} / \mathrm{D}_{\mathrm{A}} ; \mathrm{Pe}_{\mathrm{y}}=\mathrm{Dv}_{\mathrm{ym}} / \mathrm{D}_{\mathrm{A}} ; \mathrm{Pe}_{\mathrm{x}}=\mathrm{H}^{2} \mathrm{v}_{\mathrm{ym}} / \mathrm{DD}_{\mathrm{A}}
$$

Each of these parameters is useful for discussing and understanding the role of the diffusive phenomena. The first refers to the competition between the bulk and diffusive flows in the $x$ direction, just beneath the gas channels. The second refers to the same competition in the y direction in the portion of the porous medium that separates one channel from the other. The third has a different meaning, involving the comparison of the diffusion time $\mathrm{H}^{2} / \mathrm{D}_{\mathrm{A}}$ in the $\mathrm{x}$ direction and the permanence time $\mathrm{D} / \mathrm{u}$ of the gas flowing from one channel to the other.

Thus, three limit regimes taking place inside the porous layer close to the electrode have been defined [1] by comparing the axial and the transversal diffusion times (along the $y$ - and $x$-axes, respectively) to the residence time inside the porous medium itself.

Given that generally D $>>H$, it can be assumed that $\mathrm{Pe}_{\mathrm{x}}<<\mathrm{Pe}_{\mathrm{y}}$. In particular, when $\mathrm{Pe}_{\mathrm{y}}<<1$ the regime close to the electrode can be considered purely diffusive and the reagent flux depends on the mean driving force and is independent of the velocity, On the other hand, when $\mathrm{Pe}_{\mathrm{y}}>>1 \mathrm{a}$ forced regime must be considered and the effects of axial diffusion can be neglected when compared to the forced migration. In this case, two forced sub-regimes can be considered: $a$ flow rate-controlled regime (forced flow regime) with an almost complete exhaustion of the reactant $\mathrm{A}$ consistent with $\mathrm{Pe}_{\mathrm{y}}>>1, \mathrm{Pe}_{\mathrm{x}}$ $<<1$ and the flux to the electrode directly proportional to the velocity; and a forced pellicular regime, characterized by $\mathrm{Pe}_{\mathrm{y}}>>1$ and $\mathrm{Pe}_{\mathrm{x}}>>1$ with the flux to the electrode proportional to the squared root of the velocity. In the first sub-regime the entire reagent reaches the electrode, while in the second the residence time is too short for the transversal diffusion times, so that only the reagent in a thin pellicular layer near the electrode can be consumed.

\subsection{The Composition Field}

The local molar balance of the reactant A:

$$
\operatorname{div} \mathbf{N}_{\mathrm{A}}=0
$$

the total flux expression in terms of bulk and diffusive components:

$$
\mathbf{N}_{\mathrm{A}}=\mathrm{C}\left(\mathbf{v x}_{\mathrm{A}}-\mathrm{D}_{\mathrm{A}} \operatorname{gradx} \mathrm{x}_{\mathrm{A}}\right)
$$

and the continuity equation and the motion equation in the Darcy form Equation (1), lead to the partial differential equation:

$$
\left(1 / D_{A}\right)\left(\operatorname{vgradx}_{\mathrm{A}}\right)-\nabla^{2} \mathrm{x}_{\mathrm{A}}=0
$$


where the velocity components $\mathrm{v}_{\mathrm{x}}$ and $\mathrm{v}_{\mathrm{y}}$ can be considered as known from the former, de-coupled calculation of the flow field.

If considering:

$$
\begin{gathered}
\mathrm{e}=\mathrm{x}_{\mathrm{A}} / \mathrm{x}_{\mathrm{Am}} ; \mathrm{x}_{\mathrm{Am}}=\left(\mathrm{x}_{\mathrm{A} 1}+\mathrm{x}_{\mathrm{A} 2}\right) / 2 \\
\mathbf{n}=\mathbf{N}_{\mathrm{A}} \mathrm{H} / \mathrm{D}_{\mathrm{A}} C \mathrm{x}_{\mathrm{Am}} ; \mathrm{m}=\mathrm{k} \mathrm{v}_{\mathrm{xr}} \mathrm{H} / \mathrm{D}_{\mathrm{A}}
\end{gathered}
$$

the dimensionless system:

$$
\begin{gathered}
\mathrm{m}\left(\mathrm{u}_{\mathrm{x}} \partial \mathrm{e} / \partial \mathrm{x}+\mathrm{u}_{\mathrm{y}} \partial \mathrm{e} / \partial \mathrm{y}\right)-\left(\partial^{2} \mathrm{e} / \partial \mathrm{x}^{2}+\partial^{2} \mathrm{e} / \partial \mathrm{y}^{2}\right)=0 \\
\mathrm{n}_{\mathrm{x}}=\mathrm{mev}_{\mathrm{x}}-\partial \mathrm{e} / \partial \mathrm{x} ; \mathrm{n}_{\mathrm{y}}=\mathrm{mev}_{\mathrm{y}}-\partial \mathrm{e} / \partial \mathrm{y}
\end{gathered}
$$

is obtained. A simple set of boundary conditions for the system are:

$$
\begin{array}{ccc}
\mathrm{x}=0 & 0<y<b / 2 & e=e_{1} \\
& b / 2<y<b / 2+d & \partial e / \partial x=0 \\
& b / 2+d<y<b+d & e=e_{2} \\
\mathrm{x}=1 & 0<y<b+d & \mathrm{e}=0 \\
\mathrm{y}=0 & 0<x<1 & \partial e / \partial y=0 \\
\mathrm{y}=\mathrm{b}+\mathrm{d} & 0<x<1 & \partial e / \partial y=0
\end{array}
$$

The first and the third of these conditions impose a specific composition value of the gas in the gas channels. The second, fifth and sixth conditions are obvious. The fourth is consistent with the assumption of an instantaneous reaction (that is limit current) at the electrode surface.

The first, third and fourth conditions will need a further discussion and will be modified in some of the following calculations to highlight the effects of some connected phenomena. For instance, for a reaction of finite velocity, the fourth condition must be generalized by taking into account an appropriate kinetic expression. Similarly, when the migration velocity $\mathrm{u}$ is comparable with the transport coefficient between the free gas in the gas channels and the gas trapped in the porous medium, the first and third conditions must impose the continuity of the flux at the "interface" between the two zones.

\subsection{The Sherwood Number}

When the composition field is known, the mean flux on the active surfaces of the channels can be calculated as:

$$
\mathrm{N}_{\mathrm{Axm}}=-\mathrm{CD}_{\mathrm{A}}\left(\int_{0, \mathrm{D}+\mathrm{B}}\left(\partial \mathrm{x}_{\mathrm{A}} / \partial \mathrm{X}\right)_{\mathrm{Y}=\mathrm{H}} \mathrm{dY}\right) / \mathrm{B}=-\mathrm{CD}_{\mathrm{A}} \mathrm{x}_{\mathrm{Am}}\left(\int_{0, \mathrm{~d}+\mathrm{b}}(\partial \mathrm{e} / \partial \mathrm{x})_{\mathrm{y}=1} \mathrm{dy}\right) / \mathrm{b}
$$

and compared with its expression in terms of an overall transport coefficient:

$$
\mathrm{N}_{\mathrm{Axm}}=-\mathrm{Ck}_{\mathrm{ct}} \mathrm{x}_{\mathrm{Am}}
$$

The definition Equation (18) of the overall transport coefficient $k_{\mathrm{ct}}$ implies the definition of the overall Sherwood number:

$$
\mathrm{Sh}_{\mathrm{t}}=\mathrm{k}_{\mathrm{ct}} \mathrm{H} / \mathrm{D}_{\mathrm{A}}
$$

so that it can be calculated from the composition field as:

$$
S h_{t}=(h / b) \int_{0, d+b}(\partial e / \partial x)_{y=1} d y
$$


In general, the Sherwood number of the system, $\mathrm{Sh}_{\mathrm{t}}$, depends on a number of dimensionless parameters, such as:

- $\quad$ the geometrical parameters $(\mathrm{d}, \mathrm{b})$;

- the flow parameter $\left(\mathrm{Pe}_{\mathrm{y}}\right)$;

- $\quad$ the permeability parameter $(\mathrm{k})$;

- the asymmetry parameter $\left(\mathrm{x}_{\mathrm{A} 2} / \mathrm{x}_{\mathrm{A} 1}\right)$;

- the kinetic parameters $\left(k_{\text {kin }}, a\right)$.

The effects of each of these parameters will be discussed in the following sections However, for a porous medium of given nature $(\mathrm{k})$ and geometry $(\mathrm{d}, \mathrm{b})$, limit current conditions and symmetrical constrains on the composition field $\left(\mathrm{x}_{\mathrm{A} 1} / \mathrm{x}_{\mathrm{A} 2}=1\right), \mathrm{Sh}_{\mathrm{t}}$ assumes a maximum value (that is the one corresponding to the limit current) that depends solely on the migration velocity $\left(\mathrm{Pe}_{\mathrm{y}}\right)$. In such instances, if $\mathrm{e}=\mathrm{f}\left(\mathrm{x}, \mathrm{y}, \mathrm{Pe}_{\mathrm{y}}\right)$, Equation (20) and the fourth of the conditions in Equation (16) determine the function $\mathrm{Sh}_{\mathrm{M}}\left(\mathrm{Pe}_{\mathrm{y}}\right)$. Obviously, the choice of $\mathrm{Pe}_{\mathrm{y}}$ as the basis of the argument is quite arbitrary; many other dimensionless parameters expressing the flow field could be used in its place $\left(\mathrm{Pe}_{\mathrm{x}}, \mathrm{Pe}_{\mathrm{r}}\right.$, the migration velocity $\mathrm{v}_{\mathrm{ym}}$ itself, etc.).

\section{Results of the Numerical Calculation}

The partial derivative systems Equations (6), (7), (15) and (16) have been solved by means of a numerical code based on a relaxation convergence method.

\subsection{The Flow Field}

The results for the flow field are rather obvious. They can be seen in Figure 2 and show, in particular, that

- the velocity field is characterized by some symmetry properties: the velocity module, the $y$ component and the absolute value of the $\mathrm{x}$ component are symmetrical to the geometrical axis of symmetry;

- the velocity values are proportional to the pressure difference imposed: under constant density and low Reynolds numbers, the flow problem is linear;

- the migration velocity through the porous medium is almost uniform, so that a unique mean value $\mathrm{v}_{\mathrm{ym}}=\int_{0,1} \mathrm{v}_{\mathrm{y}} \mathrm{dx}$ is a rather good approximation of the entire field.
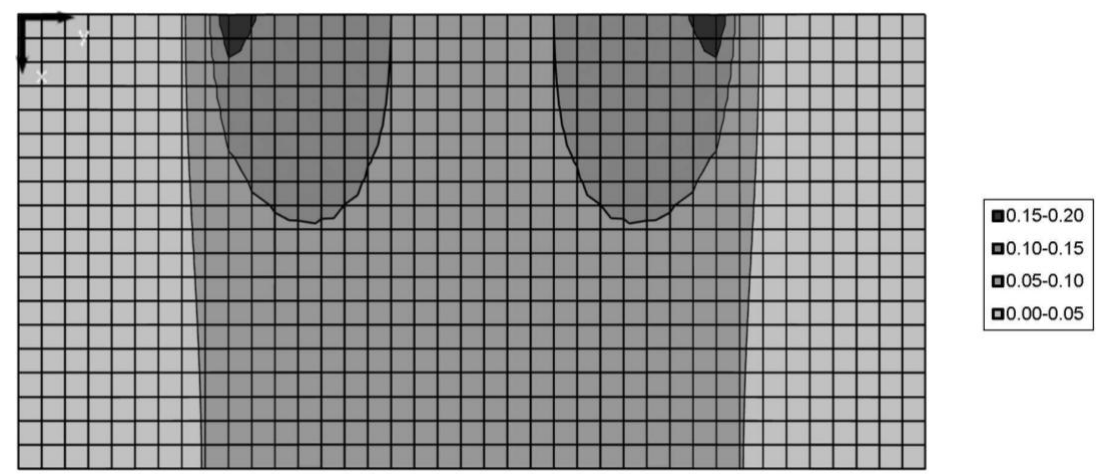

Figure 2. The absolute value of the reduced velocity field for $P e_{y}=100 ; B / D=1 ; H / D=0.1$.

\subsection{The Composition Field}

The results for the composition field provide more interesting conclusions. Figure 3 refers to different flow conditions, ranging from $\mathrm{Pe}_{\mathrm{y}}=0$ to $\mathrm{Pe}_{\mathrm{y}}=300$ and symmetrical boundary conditions 
$\left(\mathrm{x}_{\mathrm{A} 1}=\mathrm{x}_{\mathrm{A} 2}\right)$, always under the limit current assumption $\left(\mathrm{x}_{\mathrm{A}}=0\right.$ for $\left.\mathrm{X}=\mathrm{H}\right)$ and a given shape for the porous medium. Under such conditions, the concentration field, in the absence of a velocity field (Figure $3 \mathrm{a}, \mathrm{Pe}_{\mathrm{y}}=0$ ), is obviously symmetrical. On the other hand, when the velocity field becomes significant (Figure 3b, $\mathrm{Pe}_{\mathrm{y}}=100$; Figure $3 \mathrm{c}, \mathrm{Pe}_{\mathrm{y}}=300$ ), a decidedly asymmetrical composition field is achieved, where the mean thickness of the "exhausted" or "void" layer close to the electrode depends on the mean migration velocity $\mathrm{v}_{\mathrm{ym}}$, becoming thinner as the mean velocity increases.

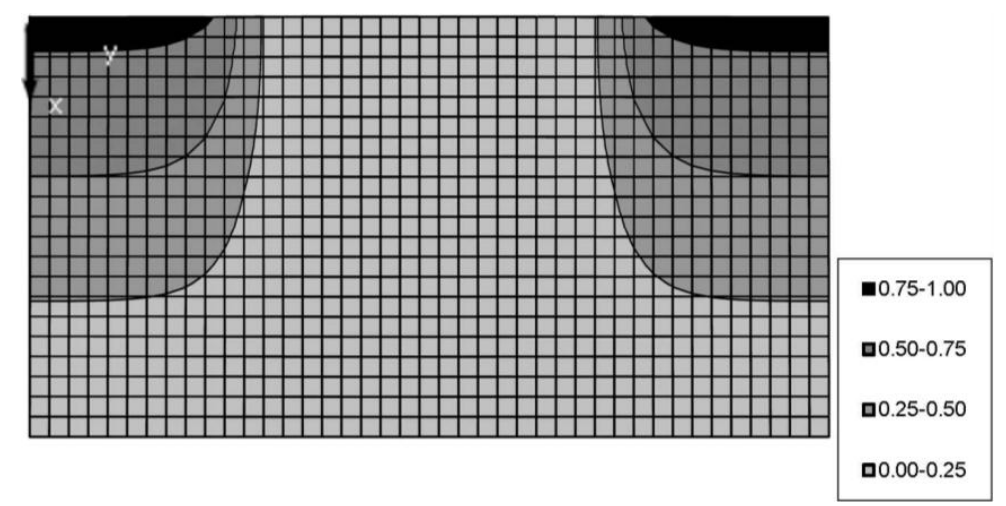

(a)

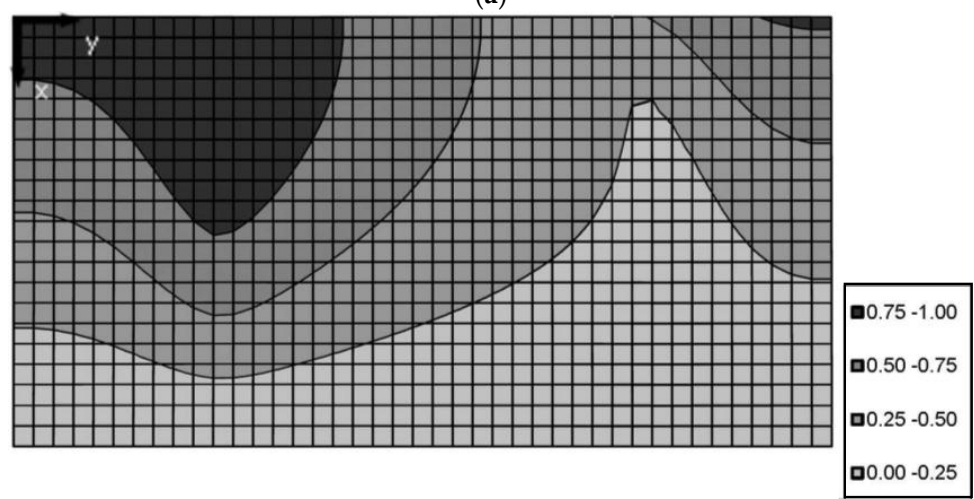

(b)

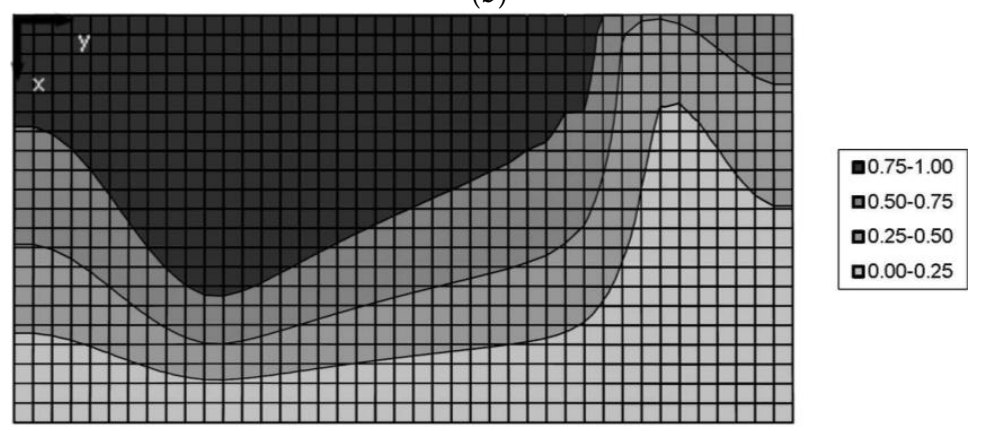

(c)

Figure 3. Reduced composition field in the control volume as a function of the velocity field, as summarized by the Peclet number $P e_{\mathrm{y}} . \mathrm{B} / \mathrm{D}=1 ; \mathrm{H} / \mathrm{D}=0.1 ; \mathrm{x}_{\mathrm{A} 1}=\mathrm{x}_{\mathrm{A} 2}$; limit current: (a) $\mathrm{Pe}_{\mathrm{y}}$ = 0 ; (b) $P e_{\mathrm{y}}=100$; and (c) $\mathrm{Pe}_{\mathrm{y}}=300$.

No clear situation directly related to forced limit regimes [1] can be determined from an examination of Figure 3, as a B/D ratio of the order of unity does not allow a clear distinction between regimes. Nevertheless, Figure $3 \mathrm{c}$ recalls in some ways a forced pellicular regime, while Figure $3 \mathrm{~b}$ is perhaps more consistent with a forced flow regime. 


\subsection{The Sh(Pe) Function}

When the composition field is defined in terms of a Sherwood number, the significance and usefulness of the limit regimes is more evident. In Figure 4, an example of the calculated $\operatorname{Sh}_{\mathrm{M}}\left(\operatorname{Pe}_{\mathrm{y}}\right)$ function is reported and it is compared to the approximate calculations derived from the definition of the three flow-limit regimes (diffusive, forced flow, forced pellicular).

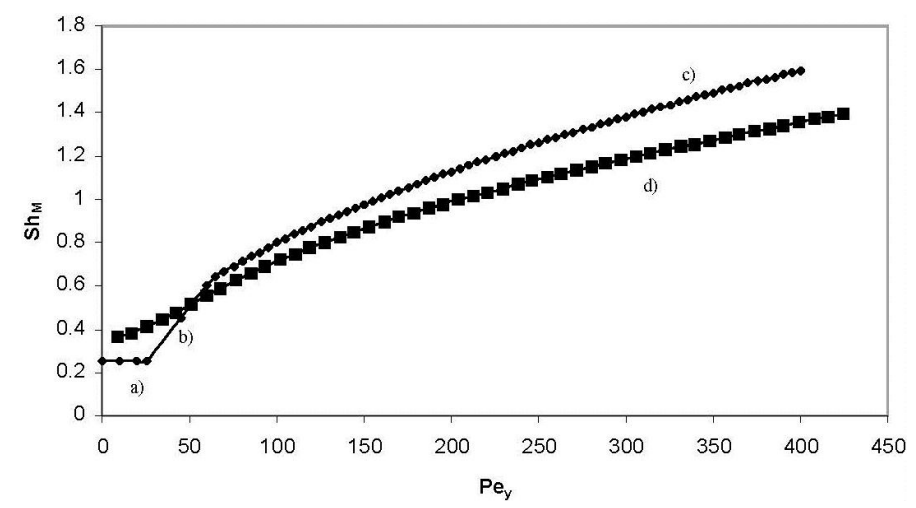

Figure 4. $\mathrm{Sh}_{\mathrm{M}}\left(\mathrm{Pe}_{\mathrm{y}}\right)$ trend. The results (d) of the numerical calculation compared to the approximate solutions of: (a) the diffusive regime; (b) the forced flow regime; and (c) the forced pellicular regime. $\mathrm{B} / \mathrm{D}=1 ; \mathrm{H} / \mathrm{D}=0.2 ; \mathrm{x}_{\mathrm{A} 1}=\mathrm{x}_{\mathrm{A} 2} ;$ limit current.

The agreement between the results of the more rigorous numerical calculations and the approximate evaluation [1] can justify the use of the approximate method just when rapid, preliminary indications are needed.

On the other hand, the errors in the approximate solutions are not negligible, especially for short migration paths $(\mathrm{D} / \mathrm{B}<1$ or $\mathrm{H} / \mathrm{D}>0.1)$. In many instances, only a more rigorous estimation of the composition field can lead to a truly reliable and precise value of the Sherwood number and, then, the limit current. Such a rigorous determination also allows a detailed and accurate description of the diffusive constraints on the local electrochemical kinetics and a completely reliable comparison of the various geometrical arrangements used for the distribution of the reactants.

The effect of the thickness of the diffusive layer is considered in Figure 5. Relatively thick layers $(\mathrm{H} / \mathrm{D}>0.1)$, which penalize diffusion, are more susceptible to significant enhancements of the transport characteristics when an increasing flow field is imposed. On the contrary, relatively thin layers $(\mathrm{H} / \mathrm{D}<0.05)$ have a better diffusive performance, but they are rather refractory in respect to the superimposition of a flow field, so that they give worse results than thicker layers at high $\mathrm{Pe}_{\mathrm{y}}$.

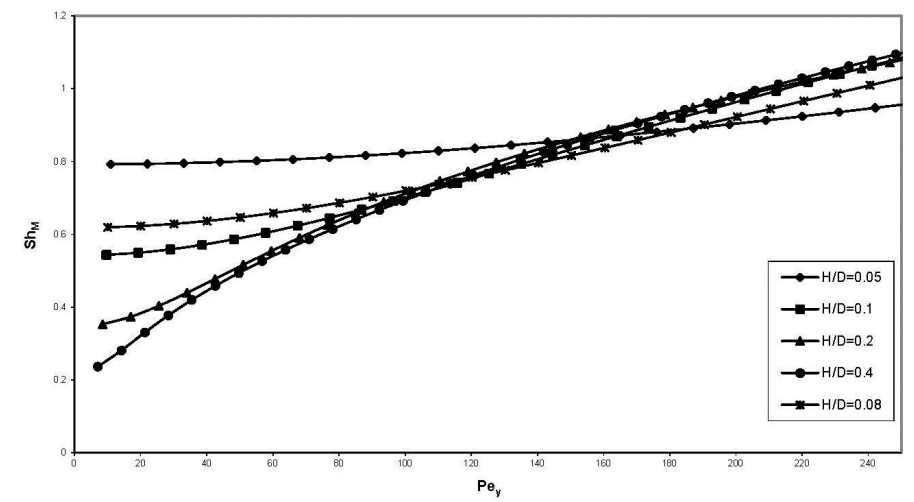

Figure 5. Dependence of the $\mathrm{Sh}_{\mathrm{M}}\left(\mathrm{Pe}_{\mathrm{y}}\right)$ function on the thickness of the diffusive layer. $\mathrm{B} / \mathrm{D}=1$; $\mathrm{x}_{\mathrm{A} 1}=\mathrm{x}_{\mathrm{A} 2} ;$ limit current; $\mathrm{H} / \mathrm{D}$ ranges from 0.05 to 0.4 . 
The effect of the length of the diffusive layer (D in Figure 1) is considered In Figure 6. Relatively short layers $(\mathrm{D} / \mathrm{B}<1)$ have an obvious better diffusive performance. On the contrary, long layers $(\mathrm{D} / \mathrm{B}>1)$ start with a poor diffusive condition and have a good performance only when a relatively high migration velocity is imposed.

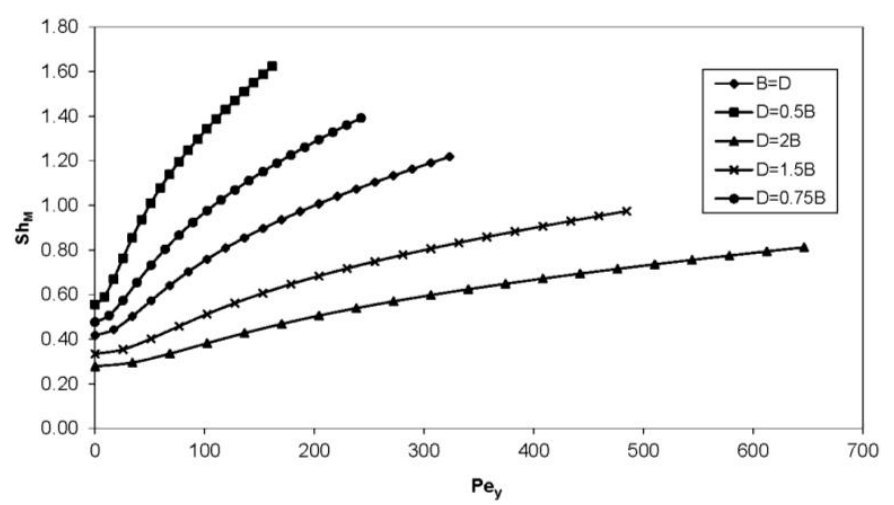

Figure 6. Dependence of the $\mathrm{Sh}_{\mathrm{M}}\left(\mathrm{Pe}_{\mathrm{y}}\right)$ function on the length of the diffusive layer. $\mathrm{H} / \mathrm{D}=0.1$; $\mathrm{x}_{\mathrm{A} 1}=\mathrm{x}_{\mathrm{A} 2} ;$ limit current; $\mathrm{B} / \mathrm{D}$ ranges from 0.5 to 2 .

The results summarized in Figures 5 and 6 highlight how the limit current performance of the electrode can be improved, just as the interdigitated and serpentine geometrical arrangements have done in practice. Moreover, they stress an apparently trivial consideration and provide a quantitative ground for a deeper reasoning: the Sherwood numbers, which are the diffusive characteristics of an electrode, can be improved either by increasing the migration velocity or by developing better geometrical arrangements, in particular by reducing the length $(\mathrm{D} / \mathrm{B})$ and thickness $(\mathrm{H})$ of the migration zone, as expected $[32,33]$.

\subsection{Asymmetry Effects}

The above results refer to symmetrical boundary conditions imposed on the composition $\left(\mathrm{x}_{\mathrm{A} 1}=\mathrm{x}_{\mathrm{A} 2}\right)$, while a certain degree of asymmetry is usually expected in interdigitated and serpentine arrangements. Figure 7 provides an answer to this problem, showing a comparison of a symmetrical case $\left(\mathrm{x}_{\mathrm{A} 1}=\mathrm{x}_{\mathrm{A} 2}\right)$ and a completely asymmetrical one $\left(\mathrm{x}_{\mathrm{A} 2}=0\right)$.

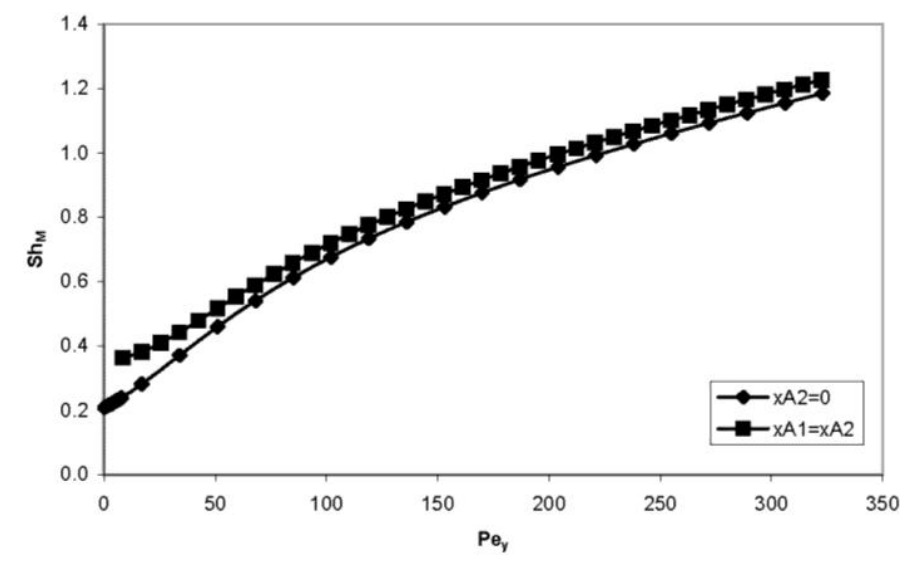

Figure 7. Dependence of the $\mathrm{Sh}_{\mathrm{M}}\left(\mathrm{Pe}_{\mathrm{y}}\right)$ function on the asymmetry of the boundary conditions. $\mathrm{B} / \mathrm{D}=1$; $\mathrm{H} / \mathrm{D}=0.1$; limit current; $\mathrm{x}_{\mathrm{A} 1}=\mathrm{x}_{\mathrm{A} 2}$ for the upper curve and $\mathrm{x}_{\mathrm{A} 2}=0$ for the lower one.

Significant differences between the two cases can be appreciated only at low migration velocities (low $\mathrm{Pe}_{\mathrm{y}}$ ). In particular, in pure diffusive cases, the Sherwood number of the asymmetrical condition 
is, as it would be expected, about one half of that of the symmetrical condition; on the other hand, the diffusive cases correspond to classical configurations where symmetrical conditions are quite probable. On the contrary, for medium and high velocities, the impact of the differences due to the asymmetry in the boundary conditions on the composition is inconsequential, so that the following conclusion can be drawn: for $\mathrm{Pe}_{\mathrm{y}}>50$, the $\mathrm{Sh}\left(\mathrm{Pe}_{\mathrm{y}}\right)$ function is substantially independent of the downstream boundary condition $\left(\mathrm{x}_{\mathrm{A} 2}\right)$. In the range $0<\mathrm{Pe}_{\mathrm{y}}<50$, a weighted average of the symmetrical and asymmetrical results:

$$
\operatorname{Sh}\left(\mathrm{x}_{\mathrm{A} 1}, \mathrm{x}_{\mathrm{A} 2}\right)=\left[\mathrm{Sh}\left(\mathrm{x}_{\mathrm{A} 1}-\mathrm{x}_{\mathrm{A} 2}, 0\right)\left(\mathrm{x}_{\mathrm{A} 1}-\mathrm{x}_{\mathrm{A} 2}\right)+\mathrm{Sh}\left(\mathrm{x}_{\mathrm{A} 2}, \mathrm{x}_{\mathrm{A} 2}\right) \mathrm{x}_{\mathrm{A} 2}\right] / \mathrm{x}_{\mathrm{A} 1}
$$

will give sufficient accuracy, covering in that way the range that is more interesting for interdigitated and serpentine arrangements.

\subsection{Electrochemical Effects}

The interaction of transport and electrochemical phenomena is considered in Figure 8. In the presence of finite electrochemical kinetics, the boundary condition at the electrode surface can no longer be simply $\mathrm{x}_{\mathrm{A}}=0$; on the contrary, it must be stated the relationship between the A flux to the electrode and the reaction rate:

$$
\mathrm{x}=1 ; 0<\mathrm{y}<\mathrm{b}+\mathrm{d} ; \mathrm{de} / \partial \mathrm{x}=\mathrm{r}_{\mathrm{A}} \mathrm{H} /\left[\mathrm{CD}_{\mathrm{A}} \mathrm{x}_{\mathrm{Am}}\right]=\mathrm{Sh}_{\mathrm{kin}} \mathrm{x}_{\mathrm{A}}^{\mathrm{a}} / \mathrm{x}_{\mathrm{Am}}
$$

where $r_{A}$ represents the reaction rate of the key reactant A per electrode surface unit. In many instances, $r_{A}$ can be assumed to be of an order a in respect to $A$ :

$$
\mathrm{r}_{\mathrm{A}}=\mathrm{k}_{\mathrm{kin}} \mathrm{C} \mathrm{x}_{\mathrm{A}}^{\mathrm{a}}
$$

with the reaction constant depending on the temperature and, especially, on the voltage loss occurring at the electrode. In some instances, a first order reaction is a sufficient approximation, just as it happens at the anode $(\mathrm{A}=$ hydrogen$)$ of a PEMFC.

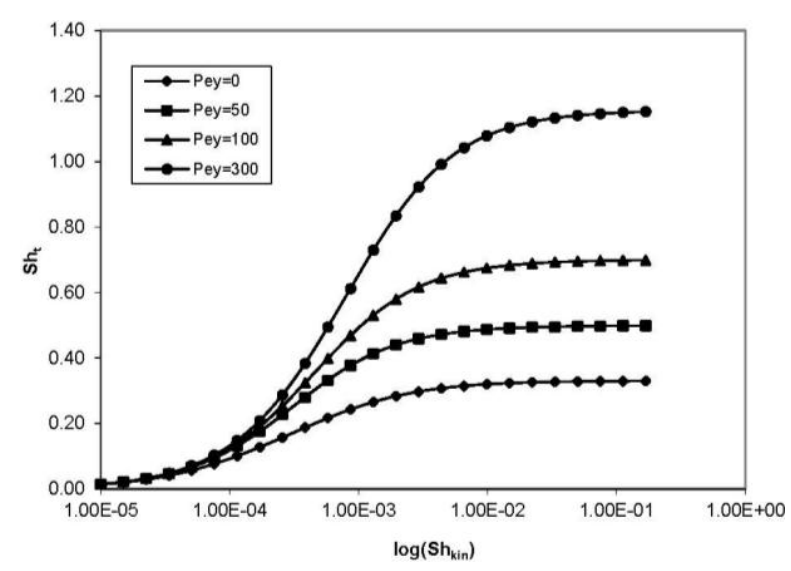

Figure 8. Effect of the electrochemical kinetics. For each $\mathrm{Pe}_{\mathrm{y}}$ the reduced total flux at the electrode $\mathrm{Sh}_{\mathrm{t}}$ ranges from zero to the maximum value $\mathrm{Sh}_{\mathrm{M}}$ (limit current). (B/D =1; H/D = 0.1; $\mathrm{x}_{\mathrm{A} 1}=\mathrm{x}_{\mathrm{A} 2}$; $\mathrm{Pe}_{\mathrm{y}}$ ranges from 0 to 300 ).

For given, finite, kinetics, the overall performance of the electrode $\mathrm{Sh}_{\mathrm{t}}$ depends on the kinetic constant k or, in dimensionless terms, the kinetic Sherwood number:

$$
\mathrm{Sh}_{\mathrm{kin}}=\mathrm{k}_{\mathrm{kin}}[\mathrm{H}(\mathrm{D}+\mathrm{B}) / \mathrm{B}] / \mathrm{D}_{\mathrm{A}}
$$


which increases, as $\mathrm{k}$ increases, from zero to the maximum value $\mathrm{Sh}_{\mathrm{M}}$. Figure 8 shows this monotonic trend for different values of $\mathrm{Sh}_{\mathrm{M}}\left(\mathrm{Pe}_{\mathrm{y}}\right)$.The flux parameter $\mathrm{Sh}_{\mathrm{t}}$ in ordinates is reported with a linear scale, so that it can be considered proportional to the current density. On the other hand, the kinetic parameter $\mathrm{Sh}_{\text {kin }}$ in abscissa is reported with a logarithmic scale, so that it can be considered proportional to the voltage losses. In such a way, each curve of Figure 8 strictly resembles a characteristic curve of the electrode.

Each curve starts at zero (open circuit, $S h_{\text {kin }}=0$ ), then shows a segment where $S h_{t} \approx S h_{\text {kin }}$ (kinetics controlling, $\mathrm{Sh}_{\mathrm{kin}}<<\mathrm{Sh}_{\mathrm{M}}$ ) and terminates with a segment where $\mathrm{Sh}_{\mathrm{t}} \approx \mathrm{Sh}_{\mathrm{M}}$ (limit current, $\mathrm{Sh}_{\mathrm{kin}}>\mathrm{Sh}_{\mathrm{M}}$ ). The advantage of having high Peclet numbers and, correspondingly, high Sherwood numbers $\left(\mathrm{Sh}_{\mathrm{M}}\right)$ is evident: higher current density can be achieved for equal voltage losses.

\subsection{The Harmonic Mean Approximation}

For a rapid evaluation of $S h_{t}$, starting with the knowledge of $S h_{\text {kin }}$ (related to voltage) and $\mathrm{Sh}_{\mathrm{M}}$ (related to limit current), the classical harmonic mean can be used:

$$
\mathrm{Sh}_{\mathrm{t}}=\left(1 / \mathrm{Sh}_{\mathrm{kin}}+1 / \mathrm{Sh}_{\mathrm{M}}\right)^{-1}
$$

For linear electrode kinetics $(\mathrm{a}=1)$ and low $\mathrm{Sh}_{\mathrm{M}}$ (diffusive conditions), the rapid estimation of Equation (25) gives very good results comparable to the rigorous calculation in Equation (20) and the composition field obtained through the boundary Conditions (21). This good agreement depends, first of all, on a careful and coherent definition of the limit parameters $S h_{\text {kin }}$ and $S h_{M}$ : Equation (25) is appropriate only if the constraints:

$$
S h_{\text {kin }}=\lim _{k_{\text {kin }} \rightarrow 0} S h_{t} ; S h_{M}=\lim _{k_{\text {kin }} \rightarrow \infty} S h_{t}
$$

are directly used to define $\mathrm{Sh}_{\text {kin }}$ and $\mathrm{Sh}_{\mathrm{M}}$ from $\mathrm{Sh}_{\mathrm{t}}$ data or theoretical considerations on the $\mathrm{Sh}_{\mathrm{t}}$ trend.

On the other hand, the results are less accurate for high $\mathrm{Sh}_{\mathrm{M}}$ : in fact, the harmonic mean Equation (25) is automatically correct only when the diffusive and the reactive paths work strictly in series; on the contrary, in the system considered here, the diffusion and the reaction at the electrode surface work more in a series-parallel manner, so that Equation (25) must be considered as an approximation which respects the two asymptotic Solutions (26), but is affected by an appreciable error for intermediate conditions. The significance of these errors, which may even reach $15 \%-20 \%$, can be better appreciated in Figure 9.

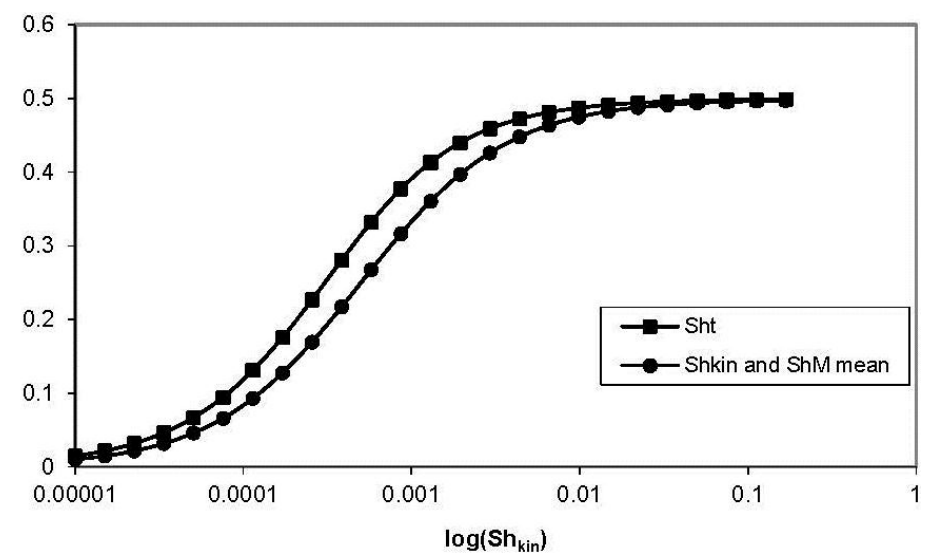

Figure 9. Errors introduced by using the harmonic mean between $S_{\text {kin }}$ and $S h_{M}$. $(B / D=1 ; H / D=0.1$; $\left.\mathrm{x}_{\mathrm{A} 1}=\mathrm{x}_{\mathrm{A} 2} ; \mathrm{Pe}_{\mathrm{y}}=50\right)$. 
Because of the above considerations, a relevant practical conclusion can be stressed: for any kind of geometrical or fluidynamically-complex electrode, the knowledge of the limit current and the intrinsic electrode kinetics are not fully sufficient for an accurate a-priori estimation of the characteristic curve. This is also the conclusion of a more specific and wider study of complex electrodes $[34,35]$.

\section{Different Electrodes}

As already stated, only a precise and reliable estimation of the Sherwood number provides a detailed and accurate description of the local electrochemical kinetics and a reliable comparison of the various geometrical arrangements used for the distribution of the reactants. In turn, a better understanding of these features will allow us to plan more effectively the geometrical optimization of the cell. However, the ultimate goal of obtaining high uniform Sherwood numbers in all parts of the cell plane and low head losses can be still problematic.

As a matter of fact, both interdigitated and serpentine electrodes can be operated at high Sherwood numbers corresponding to high limit currents [6,24], but both are correspondingly penalized by higher head losses than traditional electrodes. An example of this trend is reported in Figure 10 for a permeability parameter equal to 0.35 [24].

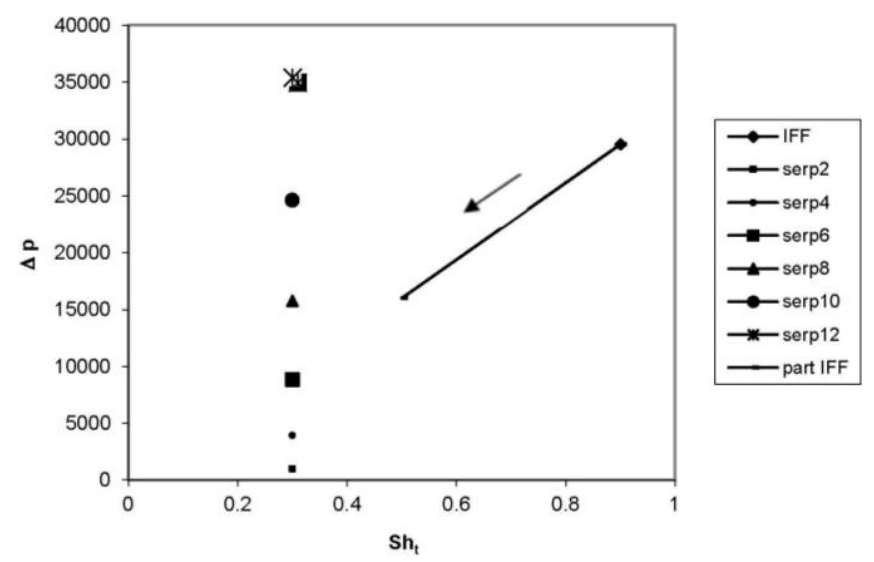

Figure 10. A comparison of the running conditions, in terms of head losses and diffusive resistances, for different electrode arrangements. Serpentine (serp with number of zigzag), interdigitated flow field (IFF) and partially interdigitated (part IFF) configurations are considered. (B/D = 1; H/D = 0.1; permeability parameter $=0.35$ ).

The interdigitated arrangement allows a substantial increase in the Sherwood number at the cost of very high head losses.

The improved performance of the interdigitated solution in spite of a higher pressure drop is confirmed by experimental literature data in comparison to the parallel configuration $[15,36]$.

Nevertheless, Figure 10 shows that a serpentine electrode only provides limited improvements to the Sherwood number with an increase in the head losses, which become prohibitive as the zigzag number increases. Neither serpentine nor interdigitated electrodes seem to be able to supply a completely satisfactory answer to the optimization problem at the moment. The partially interdigitated configuration proposed [24] where only a fraction $\varphi$ (degree of interdigitation) passes through the porous medium from a channel to the next, thanks to calibrated holes which allow low localized head losses, could offer another answer, with a promising step in the right direction. Indeed, as reported in Figure 10, partially-interdigitated electrodes have a rather extensive performance range, from that of a completely interdigitated electrode to that similar to serpentine electrodes.

The need of a similar compromise is confirmed by the literature, where different solutions are studied, up to innovative proposals as PEMFC flow-field capable of switching between parallel and interdigitated configurations as a function of the operating conditions [36]. 


\section{Conclusions}

In previous works, mass transfer phenomena in PEMFC electrodes were analyzed in terms of the interactions between diffusive and forced flows. All the phenomena could be summarized by expressing the Sherwood number as a function of the Peclet number. The $\mathrm{Sh}(\mathrm{Pe})$ approximation function that was initially deduced by determining three different flow regimes has now been improved through a numerical description based on simple reference conditions and a number of corrective coefficients and averaging methods. The comparison of the approximate and the more precise descriptions has shown that the former were substantially correct and useful for rapid, preliminary calculations but the errors in these approximate solutions are not fully negligible. Only a more precise and reliable estimation of the Sherwood numbers can provide detailed and precise correlations for the local electrochemical kinetics and, then, a useful comparison of the various geometrical arrangements used for the distribution of the reactants.

In particular, the effects of the electrode geometry, the asymmetry of the boundary conditions and the interactions between the intrinsic electrode kinetics and mass transfer phenomena have been considered here. It has also been shown that for any kind of geometrically or fluidynamically complex electrode, a knowledge of the limit current and the intrinsic electrode kinetics is not sufficient for an accurate a-priori estimation of the characteristic curve, but also the interaction with the flow field has to be investigated.

Finally, the different electrode configurations have been studied in depth and it has been found that interdigitated and serpentine electrodes can be operated at high limit currents, but at the cost of higher head losses than in the case of traditional electrodes. Thus, at the present time, both serpentine and interdigitated electrodes do not seem to offer a completely satisfactory answer to the problem of electrode optimization. Alternative solutions may be found in using special distribution grids or a partially interdigitated configuration, solutions which can be easily compared and investigated following the proposed approach.

Acknowledgments: The authors whish remember with gratitude the memory of prof. Costa, esteemed teacher who headed the research team to study the PEMFC cells according to the approach presented here.

Author Contributions: Elisabetta Arato and Barbara Bosio collaborated to state the theoretical model; Marzia Pinna developed and solved the numerical code; Michela Mazzoccoli analysed literature data and compared results.

Conflicts of Interest: The authors declare no conflict of interest.

Symbols
a
A
b
B
C
d
D
$D_{A}$
e
$\mathrm{H}$
k
$k_{c t}$
$k_{k i n}$
K
n
$N_{A}$
m $=k P_{r}$
p
P

Order of reaction

Key reactant of the electrode reaction

Dimensionless width of a channel

Width of a channel

Molar concentration

Dimensionless length of the diffusive layer

Length of the diffusive layer

Effective diffusivity in the porous medium

Dimensionless composition variable (see Equation (14))

Thickness of the diffusive layer

Dimensionless permeability of the porous medium

Overall transport coefficient

Reaction constant

Permeability of the porous medium

Vectorial dimensionless flux

Vectorial molar flux of A

See Equation (14)

Dimensionless pressure

Absolute pressure

-
-
$\mathrm{m}$
$\mathrm{kmol} / \mathrm{m}^{3}$
-
$\mathrm{m}$
$\mathrm{m}^{2} / \mathrm{s}$
-
$\mathrm{m}$
-
$\mathrm{m} / \mathrm{s}$
$\mathrm{m} / \mathrm{s}$
$\mathrm{m}^{2}$
-
$\mathrm{kmol} / \mathrm{m}^{2} \cdot \mathrm{s}$
-
-
$\mathrm{Kg} / \mathrm{m} \cdot \mathrm{s}^{2}$




$\begin{array}{lll}\text { Pe } & \text { PECLET number } & - \\ \mathrm{r}_{\mathrm{A}} & \text { Reaction rate of A for unit electrode surface } & \mathrm{kmol} / \mathrm{m}^{2} \cdot \mathrm{s} \\ \mathrm{Sh} & \text { SHERWOOD number } & - \\ \mathbf{u} & \text { Vectorial dimensionless velocity } & - \\ \mathbf{v} & \text { Vectorial velocity } & \mathrm{m} / \mathrm{s} \\ \mathrm{v}_{\mathrm{xr}} & \text { Reference velocity for v (see Equation (3)) } & \mathrm{m} / \mathrm{s} \\ \mathrm{x}_{\mathrm{A}} & \text { Mole fraction } & - \\ \mathrm{x} & \text { Dimensionless X coordinate } & - \\ \mathrm{y} & \text { Dimensionless Y coordinate } & - \\ \mathrm{X} & \text { Spatial coordinate, perpendicular to the electrode } & \mathrm{m} \\ \mathrm{Y} & \text { Spatial coordinate, parallel to the electrode } & \mathrm{m} \\ \mu & \text { Viscosity of the gas } & \mathrm{kg} / \mathrm{m} \cdot \mathrm{s} \\ \mathrm{Indexes} & & \\ 1 & \text { First channel } & \\ 2 & \text { Second channel } & \\ \mathrm{kin} & \text { Kinetic } & \\ \mathrm{m} & \text { Mean } & \\ \mathrm{M} & \text { Maximum } & \\ \mathrm{r} & \text { Reference } & \\ \mathrm{t} & \text { Overall } & \\ \mathrm{x} & \text { X axis } & \\ \mathrm{y} & \text { Y axis } & \\ & & \end{array}$

\section{References}

1. Arato, E.; Costa, P. Gas-phase mass-transfer resistance at PEMFC electrodes. Part 1—Diffusive and forced migration through a porous medium. J. Power Sources 2006, 158, 200-205. [CrossRef]

2. Ge, S.H.; Yi, B.L. A mathematical model for PEMFC in different flow modes. J. Power Sources 2003, 124, 1-11. [CrossRef]

3. Serrafero, A.; Arato, E.; Costa, P. Transport phenomena and performance limits in polymeric electrolyte membrane fuel cells. J. Power Sources 2005, 145, 470-476. [CrossRef]

4. Kumar, A.; Reddy, R.G. Effect of gas flow-field design in the bipolar/end plates on the steady and transient state performance of polymer electrolyte membrane fuel cells. J. Power Sources 2006, 155, 264-271. [CrossRef]

5. Karvonen, S.; Hottinen, T.; Saarinen, J.; Himanen, O. Modeling of flow field in polymer electrolyte membrane fuel cell. J. Power Sources 2006, 161, 876-884. [CrossRef]

6. Ahmed, D.H.; Sung, H.J. Effects of channel geometrical configuration and shoulder width on PEMFC performance at high current density. J. Power Sources 2006, 162, 327-339. [CrossRef]

7. Chiu, H.C.; Jang, J.H.; Yan, W.M.; Li, H.Y.; Liao, C.C. A three-dimensional modeling of transport phenomena of proton exchange membrane fuel cells with various flow fields. Appl. Energy 2012, 96, 359-370. [CrossRef]

8. Guo, N.; Leu, M.C.; Koylu, U.O. Optimization of Parallel and Serpentine Configurations for Polymer Electrolyte Membrane Fuel Cells. Fuel Cells 2014, 14, 876-885. [CrossRef]

9. Costamagna, P. Transport phenomena in polymeric membrane fuel cells. Chem. Eng. Sci. 2001, 56, $323-332$. [CrossRef]

10. Fuller, T.F.; Newman, J. Water and thermal management in solid-polymer-electrolyte fuel cells. J. Electrochem. Soc. 1993, 140, 1218-1225. [CrossRef]

11. Um, S.; Wang, C.Y. Three-dimensional analysis of transport and electrochemical reactions in polymer electrolyte fuel cells. J. Power Sources 2004, 125, 40-51. [CrossRef]

12. Karthikeyan, P.; Velmurugan, P.; Abby, J.G.; Kumar, R.R.; Vasanth, R.J. Experimental investigation on scaling and stacking up of proton exchange membrane fuel cells. Int. J. Hydrog. Energy 2014, 39, 11186-11195. [CrossRef]

13. Abdollahzadeh, M.; Pascoa, J.C.; Ranjbar, A.A.; Esmaili, Q. Analysis of PEM (Polymer Electrolyte Membrane) fuel cell cathode two-dimensional modelling. Energy 2014, 68, 478-494. [CrossRef]

14. Jian, Q.F.; Ma, G.Q.; Qiu, X.L. Influences of gas relative humidity on the temperature of membrane in PEMFC with interdigitated flow field. Renew. Energy 2014, 62, 129-136. [CrossRef] 
15. Santamaria, A.D.; Cooper, N.J.; Becton, M.K.; Park, J.W. Effect of channel length on interdigitated flow-field PEMFC performance: A computational and experimental study. Int. J. Hydrog. Energy 2013, 38, 16253-16263. [CrossRef]

16. Sousa, T.; Mamlouk, M.; Scott, K.; Rangel, C.M. Three Dimensional Model of a High Temperature PEMFC. Study of the Flow Field Effect on Performance. Fuel Cells 2012, 12, 566-576. [CrossRef]

17. Chen, L.; Luan, H.B.; He, Y.L.; Tao, W.Q. Pore-scale flow and mass transport in gas diffusion layer of proton exchange membrane fuel cell with interdigitated flow fields. Int. J. Therm. Sci. 2012, 51, 132-144. [CrossRef]

18. Zhang, G.; Guo, L.; Ma, B.; Liu, H. Comparison of current distributions in proton exchange membrane fuel cells with interdigitated and serpentine flow fields. J. Power Sources 2009, 188, 213-219. [CrossRef]

19. Zhukovsky, K.; Pozio, A. Maximum current limitations of the PEM fuel cells with serpentine gas supply channels. J. Power Sources 2004, 130, 95-105. [CrossRef]

20. Ke, X.; Alexander, J.I.D.; Prahl, J.M.; Savinell, R.F. Flow distribution and maximum current density studies in redox flow batteries with a single passage of the serpentine flow channel. J. Power Sources 2014, 270, 646-657. [CrossRef]

21. Guilin, H.; Xu, Y.; Zhang, Z. Numerical Simulation of Heat/Mass Transfer in a Single Proton Exchange Membrane Fuel Cell with Serpentine Fluid Channels. Int. J. Electrochem. Sci. 2014, 9, 1902-1910.

22. Shimpalee, S.; Van Zee, J.W. Numerical studies on rib \& channel dimension of flow-field on PEMFC performance. Int. J. Hydrog. Energy 2007, 32, 842-856.

23. Arato, E.; Costa, P. Transport mechanisms and voltage losses in PEMFC membranes and at electrodes: A discussion of open-circuit irreversibility. J. Power Sources 2006, 159, 861-868. [CrossRef]

24. Arato, E.; Pinna, M.; Costa, P. Gas-phase mass-transfer resistance at PEMFC electrodes. Part 2-Effects of the flow geometry and the related pressure field. J. Power Sources 2006, 158, 206-212. [CrossRef]

25. Yi, J.S.; Van Nguyen, T. Multicomponent transport in porous electrodes of proton exchange membrane fuel cells using the interdigitated gas distributors. J. Electrochem. Soc. 1999, 146, 38-45. [CrossRef]

26. Chen, L.; Luan, H.; Feng, Y.; Song, C.; He, Y.L.; Tao, W.Q. Coupling between finite volume method and lattice Boltzmann method and its application to fluid flow and mass transport in proton exchange membrane fuel cell. Int. J. Heat Mass Trasf. 2012, 55, 3834-3848. [CrossRef]

27. Hu, G.; Fan, J.; Chen, S.; Liu, Y.; Cen, K. Three-dimensional numerical analysis of proton exchange membrane fuel cells (PEMFCs) with conventional and interdigitated flow fields. J. Power Sources 2004, 136, 1-9. [CrossRef]

28. Xiao, B.; Fan, J.; Ding, F. A fractal analytical model for the permeabilities of fibrous gas diffusion layer in proton exchange membrane fuel cells. Electrochim. Acta 2014, 134, 222-231. [CrossRef]

29. Marra, D.; Bosio, B.; Arato, E. Fluid-Dynamic Characterisation of MCFC Gas Distributors. Chem. Eng. Proc. 2009, 48, 797-807. [CrossRef]

30. Liu, S.F.; Chu, H.S.; Yuan, P. Effect of inlet flow maldistribution on the thermal and electrical performance of a molten carbonate fuel cell unit. J. Power Sources 2006, 161, 1030-1040. [CrossRef]

31. Bird, R.B.; Stewart, W.E.; Lightfoot, E.N. Transport Phenomena, 2nd ed.; Wiley: New York, NY, USA, 2007.

32. Jeng, K.T.; Lee, S.F.; Tsai, G.F.; Wang, C.H. Oxygen mass transfer in PEM fuel cell gas diffusion layers. J. Power Sources 2004, 138, 41-50. [CrossRef]

33. Chun, J.H.; Park, K.T.; Jo, D.H.; Kim, S.G.; Kim, S.H. Numerical modeling and experimental study of the influence of GDL properties on performance in a PEMFC. Int. J. Hydrog. Energy 2011, 36, 1837-1845. [CrossRef]

34. Costa, P.; Bosio, B. Diffusive resistance analysis in fuel cells: Part 1. Some theoretical considerations. J. Power Sources 2007, 172, 334-345. [CrossRef]

35. Costa, P.; Bosio, B. Diffusive resistance analysis in fuel cells: Part 2. Some methods and examples. J. Power Sources 2007, 172, 346-357. [CrossRef]

36. Santamaria, A.D.; Bachman, J.; Park, J.W. Design strategy for a polymer electrolyte membrane fuel cell flow-field capable of switching between parallel and interdigitated configurations. Int. J. Hydrog. Energy 2013, 38, 5807-5812. [CrossRef]

(C) 2016 by the authors; licensee MDPI, Basel, Switzerland. This article is an open access article distributed under the terms and conditions of the Creative Commons by Attribution (CC-BY) license (http://creativecommons.org/licenses/by/4.0/). 